Editorial

\title{
Clinical trial registration in the Eastern Mediterranean Region: a luxury or a necessity?
}

\author{
N. Al-Gasseer ${ }^{l}$ and O. Shideed ${ }^{2}$
}

Research and innovation have played a major role in the advancement of evidence-informed clinical practice globally [1]. This has resulted in enhanced health, extended life expectancy, reduction in health inequities and contributed to overall improved quality of life. Nevertheless, with the development of new drugs and devices, there is an increase in the testing of the efficacy and safety of these health interventions on human subjects before they become publically available. Clinical trials strengthen and support the generation of evidence to inform health care and clinical practice [2]. In some cases, selective reporting and publishing of clinical trial outcomes endangers the health of patients, impacts clinical practice and threatens the legitimacy of policy-makers' evidence-informed decisions $[3,4]$. These concerns call for increased transparency and accountability in the conduct, registration, reporting and publishing of results of clinical trials $[5,6]$. Scientific advancement should not compromise the health and well-being of participants, communities and countries involved in the clinical trial. Furthermore, the WHO Eleventh General Programme of Work states that, "WHO has a proactive role to play in leading a dialogue on setting priorities and ethical standards for research, as scientific advances continue, for example in clinical research, social science and genomics" [7].

In response to these concerns, many international entities have started to take measures to standardize the process of clinical trial registration. A turning point was the 2004 decision of the International Committee of Medical Journal Editors (ICMJE) that no clinical trial should and would be considered for publication unless it was registered before recruitment of the first participant [8]. This was followed by the Mexico Statement on Health Research (Ministerial Summit on Health Research), where it was recommended that Member States encourage transparency on research results and WHO in collaboration with stakeholders develop a platform to link clinical trial registries [9]. This paved the way for the establishment of the WHO International Clinical Trial Registry Platform, as a result of the discussions during the 58th World Health Assembly WHA58.34 [10]. Many countries have created clinical trials registries at the national level and supported this with regulations and legislations.

Clinical trials are on the rise in developing countries and the Eastern Mediterranean Region is no exception [11]. This poses a challenge as the protective ethics and legal frameworks are lacking or weak, if present [12]. There are many factors that have led to a shift in where clinical trials are conducted (i.e. developed versus developing countries) mainly: less stringent laws, if present, and weak regulatory mechanisms; less comprehensive legislation; lower cost of conducting the trials; larger treatment-free population; lower participant and health-care provider awareness of ethical issues pertaining to conduct of clinical trials, which leads to lower standards of accountability (towards patients, family, health professionals, countries, etc.); and ease of patient recruitment. Clinical trial registration is ethically imperative and promotes good research practice, as well as conferring other benefits such as: facilitating evidence-informed policy and research governance, ensuring that research meets national needs while complying with international standards, improving compliance with national regulations, improving collaboration among countries and minimizing duplication of initiatives, improving research visibility and identifying knowledge gaps, and promoting recruitment and participation of informed/aware individuals.

Clinical trials are an important contributor to the field of health knowledge and research for health. Clinical trials involve human participants and therefore care must be taken to ensure that there is a balance between the contribution to well-being on the one hand and the protection of well-being on the other. Registration as a means of reporting may contribute to ensuring accountability and transparency from the researcher's and funder's side as well as the right to knowledge and information from the participant's and community's side.

The current scene in the Region is characterized by only one primary registry that is linked to the WHO International Clinical Trial Registry Platform, 
the Iranian Registry for Clinical Trials. Other countries have recently developed laws that govern the conduct of clinical trials in their respective territory, such as Jordan, Syrian Arab Republic and the United Arab Emirates.

There is great variation among the countries based on the number of clinical trials registered per year with 2011 as an example [13]. Figure 1 shows distribution among the main countries where clinical trials have been registered in the WHO International Clinical Trial Registry Platform. All other countries not shown in the pie chart represent $2 \%$ of the registered clinical trials.

Regional initiatives that have promoted clinical trial registration include the Regional Director's continuous emphasis on the concern that the Region has become a fertile land for clinical trials that have not been tested nor cleared in the country of origin. Many entities are stressing the importance of creating clinical trial registries to enable registration. The commitment of the WHO Regional Office for the Eastern Mediterranean to ensure transparency in the conduct of clinical trials is in line with the recently endorsed "Strategic directions for scaling up research for health in the Eastern Mediterranean Region" and its resolution EM/RC58/R.3, which declare "ethical action" as one of the principles and call for establishing clinical trial registries respectively $[14,15]$. Additionally, in the 25th Session of the Eastern Mediterranean Advisory Committee for Health Research (2010) members identified the "lack of clinical trial registration" as a serious issue in the Region and recommended the establishment of a regional registry for clinical trials [16].

Figure 2 shows an increase in the number of registered clinical trials conducted in the Region. This is in line with the global movement towards "registration of all interventional trials is a scientific, ethical and moral responsibility" [13] referred to earlier in this paper. This graph is not indicative of the actual number of trials conducted in the Region, as many of them go unreported and unregistered.

The driving factors for clinical trial registration are rooted in the principles of transparency and accountability; information is collected to be made available for all stakeholders (decisionmakers, researchers, funders and the public) in a timely manner. Thus, registration of clinical trials facilitates research governance and stems from the right to health that should not deprive the individual and the community from the right to knowledge.

In addition to its role in compiling all data and clinical trial records in an easily accessible point, a regional registry may play an important role in: strengthening ethical and research oversight mechanisms [17], understanding the trends of trials conducted in countries of the Region over time, identifying the companies that conduct trials in the Region and the host countries, recognizing "who's who" in the clinical trial scene in the Region (funders, pharmaceuticals, researchers, etc.), and facilitating exchange of information and knowledge thereby ensuring optimal use of already limited resources and avoiding duplication of efforts. Consequently establishing a regional clinical trials registry will lead to the systematic and regulated collection of high quality evidence that serves to scientifically support health care decisions, bearing in mind that there is a moral responsibility to include reporting of negative results of trials as well. This will enable the Region to serve as a hub for high standard clinical practice that is evidence-based and promotes transparency, accountability and public availability of relevant health information.

A regional consultative meeting on establishing clinical trial registries in the Region was conducted on 31 October-1 November 2011 in the WHO Regional Office for the Eastern Mediterranean and was referred to recently in an EMHJ editorial by $\mathrm{Dr}$ M. Fathallah, Chairman of the Eastern Mediterranean Region Advisory Committee for Health Research [18]. The participants of the meeting concluded

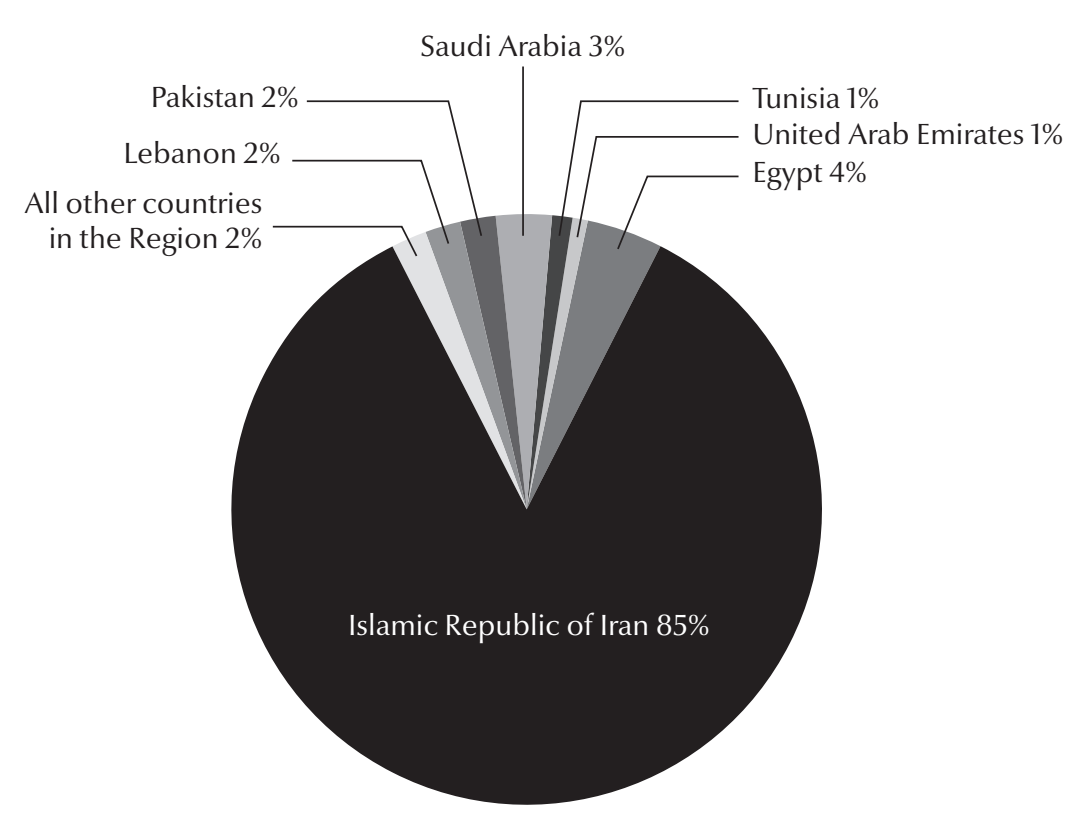

Figure 1 Clinical trials reported in the WHO International Clinical Trial Registry Platform in the Eastern Mediterranean Region for $2011(n=1443)$ (Source of data: http://apps.who.int/trialsearch/Default.aspx as of 1 January 2012) 


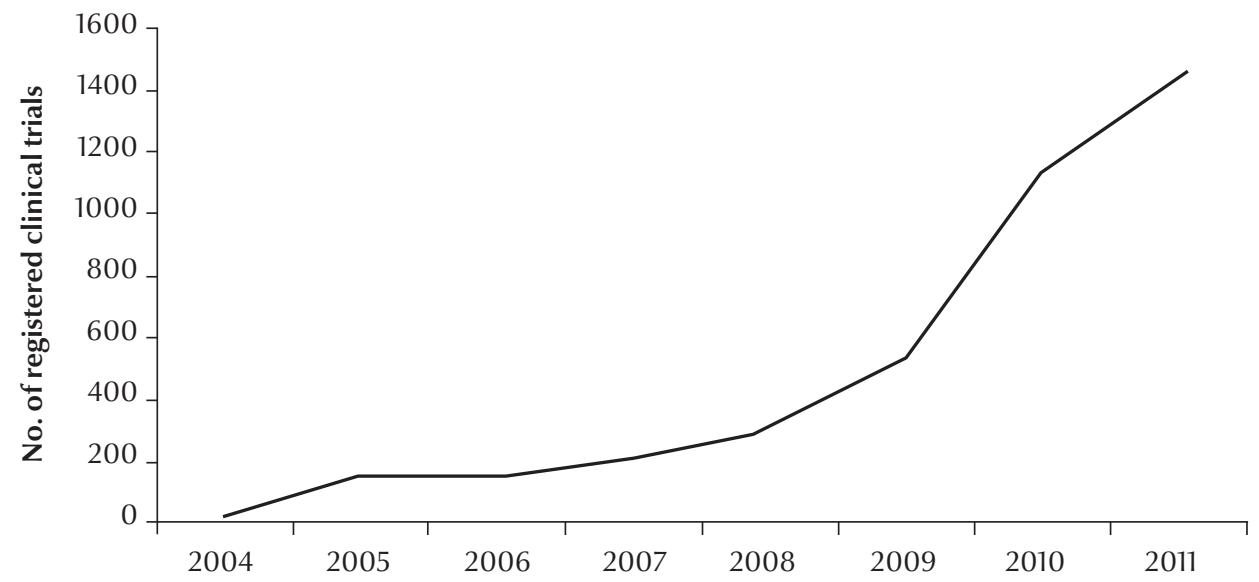

Figure 2 Trend of clinical trial registration in the Eastern Mediterranean Region (Source of data: http://apps.who.int/ trialsearch/Default.aspx as of 1 January 2012)

that the establishment of a regional registry is key to encouraging clinical trial registration in the Region. Some might argue whether legislation or development of a registry should come first. We argue that a law without a venue (registry) to implement it will not reach far and, more importantly, nor allow shared knowledge through and between networks. We believe that the presence of a registry is only the first step to providing a means for clinical trial registration in the Region. There is need for parallel steps to develop and finalize legislation at the national and regional level to make registration legally binding. The authors recommend strongly that the Eastern Mediterranean Association of Medical Editors (EMAME) issues a statement or declaration similar to that of ICMJE in 2004, which states that no clinical trial will be published without prospective registration in a publically accessible registry. Additionally, there is need for active involvement of networks such as the Evidence Informed Policy Network (EVIPNet) and the Eastern Mediterranean Region Academic Institutions Network (EMRAIN) in promoting the importance of clinical trial registration. A regional registry will not overrule or diminish national registries; on the contrary, it will promote registration and encourage countries with considerable numbers of trials to develop national registries, thereby strengthening research governance and accountability.

\section{References}

1. Sim I et al. Clinical trial registration: transparency is the watchword. Lancet, 2006, 367:1631-1633.

2. Evans T, Gulmezoglu M, Pang T. Registering clinical trials: an essential role for WHO. Lancet, 2004, 363:1413-1414.

3. Krleza-Jeric K. Building a global culture of trial registration. In: Foote M, ed. Clinical trial registries: a practical guide for sponsors and researchers of medicinal products. Basel, Switzerland, Birkhauser Verlag, 2006:59-82.

4. Viergever $\mathrm{R}$, Ghersi D. The quality of registration of clinical trials. PLoS ONE, 2011, 6:e14701

5. Krleza-Jeric $\mathrm{K}$ et al. Prospective registration and disclosure of clinical trials in the Americas: a roadmap towards transparency. Revista Panamericana de Salud Publica, 2011, 30:87-96.

6. Krleza-Jeric K, Lemmens $T$. $7^{\text {th }}$ revision of the Declaration of Helsinki: good news for the transparency of clinical trials. Croatian Medical Journal, 2009, 50:105-110.

7. World Health Organization. Engaging for health: Eleventh General Programme of Work 2006-2015: a global health agenda. Geneva, World Health Organization, 2006 (http://whqlibdoc.who.int/publications/2006/GPW_eng.pdf, accessed January 2012).
8. De Angelis $\mathrm{C}$ et al. Clinical trial registration: a statement from the International Committee of Medical Journal Editors. Annals of Internal Medicine, 2004, 141:477-478.

9. Ministerial Summit on Health research. The Mexico Statement on Health Research. Knowledge for better health: strengthening health systems. Mexico City, Ministerial Summit on Health research, 2004. (http://www.who.int/rpc/summit/agenda/ Mexico_Statement-English.pdf, accessed January 2012).

10. Ministerial Summit on Health Research. Document and resolution WHA58/34, 2005 (http://www.who.int/gb/ebwha/ pdf_files/WHA58/WHA58_34-en.pdf, accessed January 2012).

11. Leighton P. Ethics left behind in race for drug trials in the South. Science and Development Network (http://www.scidev.net/ en/news/ethics-left-behind-in-race-for-drug-trials-in-thesouth.html, accessed January 2012).

12. Lorenzo $\mathrm{C}$ et al. Hidden risks associated with clinical trials in developing countries. Journal of Medical Ethics, 2010, 36:111-115.

13. World Health Organization. International Clinical Trial Registry Platform (http://www.who.int/ictrp \& http://apps.who. int/trialsearch/Default.aspx, accessed January 2012). 
14. Strategic directions for scaling up research for health in the Eastern Mediterranean Region. Technical paper EM/RC58/6, 2011 (http://www.emro.who.int/rc58/PDF/EMRC58_06en. pdf, accessed January 2012).

15. Strategic directions for scaling up research for health in the Eastern Mediterranean Region. Resolution EM/RC58/R3, 2011 (http://www.emro.who.int/rc58/pdf/EMRC58R3_en.pdf, accessed January 2012).

16. Twenty-fifth session of the Eastern Mediterranean Advisory Committee on Health Research: Report to the Regional Director. Cairo,
World Health Organization, Regional Office for the Eastern Mediterranean, 2010 (http://www.emro.who.int/rpc/ACHR. htm, accessed January 2012).

17. Ghersi D, Pang T. En route to international clinical trial transparency. Lancet, 2008, 372:1531-1532.

18. Fathalla M. Registration of clinical trials - a regional perspective. Eastern Mediterranean Health Journal, 2012, 18:4-6. 